\title{
Influence of Physical Activity Body Mass Index on Perceived Physical Self-Concept among Undergraduate Students of Saudi Arabia
}

\author{
Varghese C Antony*, Kaukab Azeem
}

Department of Physical Education, King Fahd University of Petroleum and Minerals, Dhahran, SAUDI ARABIA.

\begin{abstract}
Background: Self-concept is one of the important aspect of our personality. Physical self-concept defined as person's perception of themselves in relation to his/her physical skills and outwards appearance. Objectives: The objective of this study was to compare and explore the association of physical activity to physical self-concept of undergraduate students at different levels of Body Mass Index (BMI). Methods: A group of 140 undergraduate students $M_{\text {age }} 19 \pm 0.70$ years randomly categorized into underweight $<18.5 \mathrm{~kg} / \mathrm{m}^{2}$ [ $\mathrm{n}=37: 26.4 \%$ ]; normal-weight $18.5-24.9 \mathrm{~kg} / \mathrm{m}^{2}$ [ $n=31$ : $22.1 \%$ ]; obese $\geq 30.00 \mathrm{~kg} / \mathrm{m}^{2}$ [ $n=37: 26.4 \%$ ] and obese class III $\geq 40.00 \mathrm{~kg} /$ $\mathrm{m}^{2}$ [ $\left.n=35: 25 \%\right]$. Physical self-concept measured using PSDQ-S. Physical activity on the basis of duration per week. Results: ANOVA revealed highly significant difference among BMI categories on all the factors of perceived physical self-concept except, health factor $(p=0.589)$. The post hoc comparison showed that obese participants had significantly lower scores on coordination $(p<0.001)$, physical activity $(p<0.05)$, sports competence $(p<0.01)$, appearance $(p<0.001)$, flexibility $(p<0.001)$, endurance $(p<$ $0.001)$, global self-esteem $(p<0.001)$ and global physical self-concept $(p$
\end{abstract}

$<0.001)$. Underweight participants reported significantly lower scores on physical activity $(p<0.001)$, sports competence $(p<0.05)$ and strength $(p$ $<0.05$ ). Conclusion: Obese category students were having poor self-concept. Normal-weight students perceived higher physical self-concept and global self-esteem than obese and underweight students. Physical activity has strong association with sports competence, strength, appearance and self-esteem. Students engaged more time in physical activity had better physical self-concept.

Key words: Body Mass Index, Perceived Physical Self-Concept, Physical Activity, Self-esteem.

\section{Correspondence}

Varghese C Antony,

King Fahd University of Petroleum and Minerals, KFUPM, Dhahran, SAUDI ARABIA. Phone no: +966-509419755

Email: vcantony@kfupm.edu.sa

DOI: 10.5330/ijpi.2019.4.39

\section{INTRODUCTION}

Self-concept is one of the most studied psychological constructs and an important aspect of our personality. Self-concept refers to the way people perceive, evaluate and think about themselves. These perceptions are based on experiences and interaction with social environment and the attributions of our own behavior. ${ }^{1}$ Self-concept develops from early childhood through adolescence and adulthood, ${ }^{2}$ becoming increasingly differentiated with age. It includes the evaluation of abilities, skills, feelings and attitudes in different areas (e.g. social, physical, academic, emotional) considered important to individuals.

Physical self-concept is an important subdomain of overall self-concept that incorporates different components such as self-perceived health, physical appearance and physical abilities. ${ }^{3}$ In sports and physical education settings, physical self-concept can be viewed either as a mediating factor that promotes physical activity and acquisition of health-related physical fitness factors as well. ${ }^{4}$ A significant association has been consistently demonstrated between physical activity and physical self-concept in children and adolescents. ${ }^{5}$

Physical Activity (PA) is any form of movement involve the large skeletal muscles that causes our body to use energy. ${ }^{6}$ PA plays a role in preventing health issues and improves the quality of life, ${ }^{7}$ also improves self-esteem, mood, energy levels, concentration and memory. ${ }^{9}$ PA aids in an individual's ability for weight management and reduces the risk of morbidity and mortality from various diseases, such as cardiovascular diseases, diabetes and high blood pressure. ${ }^{10,11}$ People who take part in competi- tive and recreational sports activities were observed to improve in their physical appearance and become more socially compatible with others.

The maintenance of adequate levels of physical activity is a critical issue among college students as they learn to cope with a new independent lifestyle. Moreover, fifty percent of the college students report a decrease in PA after high school graduation. Even though students generally have access to resources (i.e., equipment and exercise facilities), are well informed about PA and have a supportive social network. ${ }^{12,13}$ The decrease in PA is mainly attributed to their newly independent adult life away from their parents, coupled with their demanding work-study schedule. In exercise setting, physical self-concept is considered as significant antecedent of motivation, behavioral engagement and mental health outcomes. ${ }^{14-16}$ In simple terms, exercisers who feel good about their physical self are more apt to pursue exercise goals and achieve desired exercise outcomes. ${ }^{17,15}$ Much like basic need satisfaction, physical self-concept is deemed essential for realizing human potential ${ }^{14}$ and develops by internalizing experiences in one's social environment. ${ }^{18}$ The basic psychological needs and physical self-concept are constructs linked to physical activity behaviours; ${ }^{15,19}$ to promote mental health, quality of life and psychological well-being independent of physical activity. ${ }^{14,20}$

A national study in Saudi Arabia revealed that overweight and obese population are rising. ${ }^{21}$ Another study showed the prevalence of $32 \%$ overweight and obesity $15.7 \%$ among male college students in Saudi Arabia. ${ }^{22}$ In KSA, a recent study documented that $49.8 \%$ male undergraduate students were 
either overweight or obese. ${ }^{23}$ Therefore, the aim of the present study was to compare and explore the association of physical activity to perceived physical self-concept of undergraduate students at different levels of body mass index.

\section{METHODOLOGY}

\section{Participants}

For the purpose of this study 140 undergraduate students were voluntarily recruited from the King Fahd University of Petroleum and Minerals (KFUPM), Dhahran, Saudi Arabia. The sample categorized into underweight 37 (26.4\%), normal-weight 31 (22.1\%), obese 37 (26.4\%) and the remaining 35 (25\%) were in obese-III students. The age of the students were ranging from 17-21 years with mean (SD) 19 (0.70) years. On the basis of BMI, four categories were formed as underweight $<18.5$ $\mathrm{kg} / \mathrm{m}^{2}$, normal weight $18.5-24.9 \mathrm{~kg} / \mathrm{m}^{2}$, obese $\geq 30.00 \mathrm{~kg} / \mathrm{m}^{2}$ and obese class III $\geq 40.00 \mathrm{~kg} / \mathrm{m}^{2}$.

\section{Collection of Data}

The interested students were asked to provide their general individual information like (name, age, height, weight, course of study, level of exercise per week, place of stay etc); then the students were randomly selected according to their body mass index. The test procedures were explained verbally and queries and doubts if any raised were answered. A total of 152 students were participated in this survey in which 140 questionnaires were found valid and other 12 questionnaires were invalid. Participants who were not staying inside the campus and not involved in any physical activity at least for a month was excluded from the study. A written informed consent was obtained prior to the enrolment for the study and confidentiality was ensured. The data was collected through valid questionnaires which were distributed in the classroom settings. The ethical approval was obtained from the research committee, Deanship of Scientific Research, KFUPM (IN151029).

\section{Measures}

Physical self-concept was measured with short version of the Physical Self-Description Questionnaire (PSDQ-S) ${ }^{18}$ which had 40 items that measure nine specific factors of components of physical fitness and competence (i.e., strength, body fat, activity, endurance/fitness, sports competence, co-ordination, health, appearance and flexibility) and two global components (i.e., global physical competence and global selfesteem). Each declarative statement was answered on a six-point scale ranging from False (1) to True (6). This short form balances brevity and provides robust evidence for the psychometric properties of the PSDQ-S across diverse populations and physical activity settings. The reversed items on Perceived Self-Description Questionnaire-S (PSDQ-S) were recoded for the analysis so that higher scores on all items indicated higher perceived competence and more positive self-concept. Physical activity level of the participants were assessed on the basis of total duration of physical activity undertaken in minutes per week.

\section{Statistical Analyses}

Categorical data were summarized using frequency, number and percentage and continuous data were summarized using mean and Standard Deviation (SD). To determine the differences in PSDQ-S factors among BMI categories, Analysis of Variance (ANOVA) was calculated. The post hoc pairwise comparison was performed by using Bonferroni correction. A significance level of 0.05 was considered for the statistical tests. The data were analyzed with the SPSS version 24.0.

\section{RESULTS}

\section{Description of physical characteristics of the sample}

One-hundred and forty students, aged between 17 to 21 years with mean (SD) of 19 (0.70) years, were participated in this study. The sample categorized into underweight 37 (26.4\%), normal-weight 31 (22.1\%), obese $37(26.4 \%)$ and the remaining 35 (25\%) were in obese-III students. The BMI of each category was $17.26 \mathrm{~kg} / \mathrm{m}^{2}, 21.51 \mathrm{~kg} / \mathrm{m}^{2}, 36.35 \mathrm{~kg} / \mathrm{m}^{2}$ and $43.86 \mathrm{~kg} / \mathrm{m}^{2}$ respectively. In Table 1 physical activity data revealed that normal weight students engaged more hours in physical activity and very few obese students are engaged in PA more than $120 \mathrm{~min}$.

In Table 2, the reversed items on PSDQ-S (heath and body fat) factors were re-coded for the analysis so that higher scores on all items indicating higher perceived competence and more positive self-concept. The normal weight category students exhibited higher mean scores for most of the PSDQ-S factors. The results of ANOVA revealed highly significant difference among four BMI categories on in all the subscales of perceived physical self-concept with the exception of the health subscale ( $p$ $=0.589$ ). The largest difference was observed in the body fat (Figure 1; $p$-value $<0.0001)$.

When the highly significant differences were found between perceived physical self-concept between BMI categories, a post hoc pairwise comparison was performed by using Bonferroni correction presented in the Table 3.

Table 3 explains the results of post hoc pairwise comparison (with Bonferroni correction) of Perceived Physical Self-concept factors between BMI categories. Post hoc pairwise comparison analysis showed that obese-III participants had significantly lower scores on the factors: coordination

Table 1: Summary of Physical Characteristics of Participants.

\begin{tabular}{cccccc} 
Variables & $\begin{array}{c}\text { Under-weight } \\
(\mathrm{N}=37)\end{array}$ & $\begin{array}{c}\text { Normal } \\
(\mathrm{N}=31)\end{array}$ & $\begin{array}{c}\text { Obese } \\
(\mathrm{N}=37)\end{array}$ & $\begin{array}{c}\text { Obese-III } \\
(\mathrm{N}=35)\end{array}$ & $p$-value \\
\hline Age (years) & $19(1)$ & $19(1)$ & $18(1)$ & $19(1)$ & 0.001 \\
Weight(kgs) & $51.78(4.46)$ & $64.84(12.25)$ & $111.59(12)$ & $131.14(14.31)$ & $<0.001$ \\
Height $(\mathrm{cms})$ & $173(7)$ & $173(8)$ & $175(8)$ & $173(8)$ & 0.582 \\
BMI $\left(\mathrm{kg} / \mathrm{m}^{2}\right)$ & $17.26(0.87)$ & $21.51(3.05)$ & $36.35(2.02)$ & $43.86(3.38)$ & $<0.001$ \\
& & PA per Week (in minutes) & \\
$60 \mathrm{~min}$. & $17(45.9 \%)$ & $2(6.5 \%)$ & $19(51.4 \%)$ & $17(48.6 \%)$ & $<0.001$ \\
$90 \mathrm{~min}$. & $11(29.7 \%)$ & $8(25.8 \%)$ & $8(21.6 \%)$ & $8(22.9 \%)$ & \\
$120 \mathrm{~min}$. & $4(10.8 \%)$ & $9(29 \%)$ & $6(16.2 \%)$ & $8(22.9 \%)$ & \\
$150 \mathrm{~min}$. & $5(13.5 \%)$ & $12(38.7 \%)$ & $4(10.8 \%)$ & $2(5.7 \%)$ & \\
\hline
\end{tabular}

${ }^{+}$Reported as number (\% within each BMI levels) 
Table 2: Mean (SD) and ANOVA scores of Perceived Physical Self (PSDQ-S factors).

\begin{tabular}{|c|c|c|c|c|c|}
\hline PSDQ-S factors & $\begin{array}{l}\text { Under- } \\
\text { weight } \\
(N=37)\end{array}$ & $\begin{array}{l}\text { Normal } \\
(N=31)\end{array}$ & $\begin{array}{l}\text { Obese } \\
(N=37)\end{array}$ & $\begin{array}{l}\text { Obese- } \\
\text { III } \\
(N=35)\end{array}$ & $p$-value \\
\hline Health & $4.95(0.95)$ & $\begin{array}{c}5.19 \\
(0.84)\end{array}$ & $\begin{array}{c}4.99 \\
(0.96)\end{array}$ & $\begin{array}{c}4.89 \\
(0.96)\end{array}$ & 0.589 \\
\hline Coordination & $4.57(0.71)$ & $\begin{array}{c}4.87 \\
(0.77)\end{array}$ & $3.7(0.7)$ & $\begin{array}{c}3.47 \\
(1.05)\end{array}$ & $<0.001$ \\
\hline Physical Activity & $2.69(1.09)$ & $\begin{array}{c}3.84 \\
(1.24)\end{array}$ & $\begin{array}{c}2.99 \\
(0.99)\end{array}$ & $\begin{array}{c}2.89 \\
(1.06)\end{array}$ & $<0.001$ \\
\hline Body Fat & $5.74(0.42)$ & $\begin{array}{c}5.23 \\
(1.06)\end{array}$ & $\begin{array}{c}2.44 \\
(0.64)\end{array}$ & $\begin{array}{c}1.78 \\
(0.85)\end{array}$ & $<0.0001$ \\
\hline $\begin{array}{c}\text { Sports } \\
\text { Competence }\end{array}$ & $3.93(1.27)$ & $\begin{array}{c}4.72 \\
(1.06)\end{array}$ & $\begin{array}{c}3.48 \\
(1.19)\end{array}$ & $\begin{array}{c}3.3 \\
(1.13)\end{array}$ & $<0.001$ \\
\hline Appearance & $4.15(1.15)$ & $\begin{array}{c}4.72 \\
(0.87)\end{array}$ & $\begin{array}{l}3.6 \\
(0.96)\end{array}$ & $\begin{array}{l}3.63 \\
(1.3)\end{array}$ & $<0.001$ \\
\hline Strength & $3.57(1.1)$ & $\begin{array}{c}4.31 \\
(1.06)\end{array}$ & $\begin{array}{c}4.08 \\
(0.93)\end{array}$ & $\begin{array}{c}3.84 \\
(1.06)\end{array}$ & $<0.023$ \\
\hline Flexibility & $3.96(0.93)$ & $\begin{array}{c}4.34 \\
(0.97)\end{array}$ & $\begin{array}{c}2.99 \\
(0.96)\end{array}$ & $\begin{array}{c}2.62 \\
(1.01)\end{array}$ & $<0.001$ \\
\hline Endurance & $3.89(0.99)$ & $\begin{array}{l}4.14 \\
(1.3)\end{array}$ & $\begin{array}{c}2.99 \\
(1.07)\end{array}$ & $\begin{array}{c}2.61 \\
(1.16)\end{array}$ & $<0.001$ \\
\hline $\begin{array}{l}\text { Global Self- } \\
\text { Esteem }\end{array}$ & $4.69(0.8)$ & $\begin{array}{c}5.13 \\
(0.66)\end{array}$ & $\begin{array}{c}4.25 \\
(0.99)\end{array}$ & $\begin{array}{c}4.05 \\
(0.96)\end{array}$ & $<0.001$ \\
\hline $\begin{array}{l}\text { Global Physical } \\
\text { Self-Concept }\end{array}$ & $3.96(1.31)$ & $\begin{array}{c}4.41 \\
(1.12)\end{array}$ & $\begin{array}{c}2.99 \\
(1.12)\end{array}$ & $\begin{array}{c}2.65 \\
(1.26)\end{array}$ & $<0.001$ \\
\hline
\end{tabular}

Significant at 0.05 levels

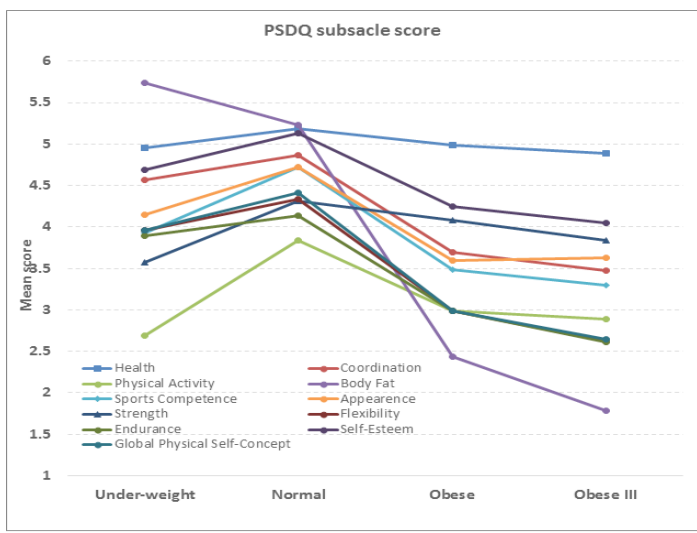

Figure 1: Mean score for Perceived Physical Self-concept factors over BMI categories.

$(p<0.001)$, physical activity $(p<0.01)$, body fat $(p<0.001)$, sports competence $(\mathrm{p}<0.01)$, appearance $(p<0.001)$, flexibility $(p<0.001)$, endurance $(p<0.001)$, global self-esteem $(p<0.001)$ and global physical self-concept $(p<0.001)$ compared to their normal-weight peers. Obese participants reported significantly lower scores on the factors coordination $(p<0.001)$, physical activity $(p<0.05)$, body fat $(p<0.001)$, sports competence $(p<0.01)$, appearance $(p<0.001)$, flexibility $(p<0.001)$, endurance $(p<0.001)$, global self-esteem $(p<0.001)$ and global physical self-concept $(p<0.001)$ than their normal-weight peers. Underweight participants reported significantly lower scores on the factors physical
Table 3: Post hoc pairwise comparison (with Bonferroni correction) of Perceived Physical Self-concept factors between BMI categories ( $\mathrm{A}$ underweight, B - normal-weight, C - obese and D - obese-III).

\begin{tabular}{|c|c|c|c|c|}
\hline $\begin{array}{l}\text { PSDQ-S } \\
\text { factors }\end{array}$ & $\begin{array}{l}\text { Under } \\
\text { Weight } \\
\text { (A) }\end{array}$ & $\begin{array}{l}\text { Normal } \\
\text { Weight } \\
\text { (B) }\end{array}$ & $\begin{array}{l}\text { Obese } \\
\text { (C) }\end{array}$ & $\begin{array}{l}\text { Obese III } \\
\text { (D) }\end{array}$ \\
\hline \multirow[t]{2}{*}{ Coordination } & $\mathrm{C}(.001)$ & $\mathrm{C}(.001)$ & & \\
\hline & $\mathrm{D}(.001)$ & $\mathrm{D}(.001)$ & & \\
\hline \multirow{3}{*}{$\begin{array}{l}\text { Physical } \\
\text { Activity }\end{array}$} & & $\mathrm{A}(.001)$ & & \\
\hline & & $\mathrm{C}(.010)$ & & \\
\hline & & $\mathrm{D}(.003)$ & & \\
\hline \multirow[t]{3}{*}{ Body Fat } & $\mathrm{B}(.039)$ & $\mathrm{C}(.001)$ & $\mathrm{D}(.002)$ & \\
\hline & $\mathrm{C}(.001)$ & $\mathrm{D}(.001)$ & & \\
\hline & $\mathrm{D}(.001)$ & & & \\
\hline \multirow{3}{*}{$\begin{array}{c}\text { Sports } \\
\text { Competence }\end{array}$} & & $\mathrm{A}(.037)$ & & \\
\hline & & $\mathrm{C}(.001)$ & & \\
\hline & & $\mathrm{D}(.001)$ & & \\
\hline \multirow[t]{2}{*}{ Appearance } & & $\mathrm{C}(.001)$ & & \\
\hline & & $\mathrm{D}(.001)$ & & \\
\hline Strength & & $\mathrm{A}(.022)$ & & \\
\hline \multirow[t]{2}{*}{ Flexibility } & $\mathrm{C}(.001)$ & $\mathrm{C}(.001)$ & & \\
\hline & $\mathrm{D}(.001)$ & $\mathrm{D}(.001)$ & & \\
\hline \multirow[t]{2}{*}{ Endurance } & $\mathrm{C}(.005)$ & $\mathrm{C}(.001)$ & & \\
\hline & $\mathrm{D}(.001)$ & $\mathrm{D}(.001)$ & & \\
\hline \multirow{2}{*}{$\begin{array}{l}\text { Global Self- } \\
\text { Esteem }\end{array}$} & $\mathrm{D}(.013)$ & $\mathrm{C}(.001)$ & & \\
\hline & & $\mathrm{D}(.001)$ & & \\
\hline \multirow{2}{*}{$\begin{array}{l}\text { Global Physical } \\
\text { Self-Concept }\end{array}$} & $\mathrm{C}(.004)$ & $C(.001)$ & & \\
\hline & $\mathrm{D}(.001)$ & $\mathrm{D}(.001)$ & & \\
\hline
\end{tabular}

The results are based on two-sided test assuming equal variances. For each significant pair, the key of the smaller category appears in the category with larger mean.

Significant at 0.05 levels

Table 4: Perceived Physical Self-concept (PSDQ-S) factors and physica activity per week.

\begin{tabular}{cccc}
\hline PSDQ-S Factors & \multicolumn{3}{c}{ Duration of physical activity per week } \\
\hline Health & $<90 \mathrm{~min}$ & $>90 \mathrm{mins}$ & $p$-value \\
Coordination & $4.89(1.08)$ & $5.2(0.53)$ & $>0.05$ \\
Physical Activity & $3.96(1.02)$ & $4.45(0.87)$ & 0.005 \\
Body Fat & $2.71(1.02)$ & $3.73(1.11)$ & $<0.001$ \\
Sports Competence & $3.6(1.93)$ & $4.06(1.76)$ & $>0.05$ \\
Appearance & $3.57(1.32)$ & $4.29(1.04)$ & 0.001 \\
Strength & $3.83(1.22)$ & $4.32(0.98)$ & 0.016 \\
Flexibility & $3.77(1.08)$ & $4.24(0.97)$ & 0.011 \\
Endurance & $3.21(1.18)$ & $3.89(1.06)$ & 0.001 \\
Self-Esteem & $3.14(1.19)$ & $3.83(1.33)$ & 0.002 \\
Global Physical Self-Concept & $3.36(1.49)$ & $3.69(1.16)$ & $>0.005$ \\
\hline
\end{tabular}


Antony and Azeem.: Physical Activity and BMI on Perceived Physical Self-Concept among Undergraduate Students of Saudi Arabia

activity $(p<0.001)$, sports competence $(p<0.05)$ and strength $(p<0.05)$ than their normal-weight peers. Moreover, underweight participants had higher scores on body fat $(p<0.001)$ indicates higher perceived positive self-concept, coordination $(p<0.001)$, flexibility $(p<0.001)$, endurance $(p<0.01)$, global self-esteem $(p<0.05)$ and global physical self-concept $(p<0.05)$ compared to obese or obese-III BMI categories.

Table 4 results showed that participants doing physical activity more than $90 \mathrm{~min}$ had significantly higher scores on the subscales coordination $(p$ $<0.01)$, physical activity $(p<0.001)$, sports competence $(p<0.01)$, appearance $(p<0.05)$, strength $(p<0.05)$, flexibility $(p<0.01)$, endurance $(p$ $<0.01)$ and overall self-esteem $(p<0.01)$ compared to the other groups doing physical activity less than $90 \mathrm{~min}$.

\section{DISCUSSION}

The present findings demonstrate that normal weight students had better perceived physical-concept than obese and underweight category students. The common belief is that an obese or underweight lack vigor, fitness and is more prone to diseases, which is reflected in the responses of perceived physical self-concept factors. The results have shown small declines in the scores of all the factors of physical self-concept in the obese and obese class III weight categories which in concurrence with the previous research outcome of self-concept. ${ }^{24,25}$

The physical self -concept is an important mediator in physical activity as well as is a valuable outcome in itself. Self-concept becomes increasingly complex (multifaceted and differentiated) as humans develop from childhood to adulthood. The results observed that physical self-concept was highly significant among BMI categories in physical activity, sports competence, appearance and strength. These findings are consistent with the results of other studies that confirm physical self-concept intimately associated with physical self-concept factors. ${ }^{26,27}$ Obesity proved to have adverse effects on both motor performance and physical self-perception..$^{28}$

Global esteem is a good evidence for better physical self-concept; and the present study demonstrated normal weight students have high self-esteem than obese groups and underweight students. Marsh $(2002)^{3}$ found a relationship that increased weight status perceived low self-esteem. Evidence indicated that self-concept is protective against depression and obesity. ${ }^{29}$ Present findings also supported the notion that students with better competence are likely to experience increase in physical self-concept, leading to enhanced global self-esteem. ${ }^{30}$

It is widely assumed that obesity is becoming increasingly predominant in many nations, including Saudi Arabia. The university has sufficient infrastructural facilities for physical activity and sports, but students are not optimizing it to their advantage. We suggested the University to provide different physical activity programs in the campus especially to the obese category of students, they will improve their physical concept factors, self-esteem and overall health. Separate clubs for obese may be created and awareness programs like eating disorders, weight management, nutrition and other activities related to obesity should be organized separately to improve their perceived physical self-concept and total health. These programs will definitely help them to improve their physical self-concept and overcome their poor body image and self-esteem which is also a barrier to their social skills. The results observed that physical self-concept very strongly linked between physical activity, sports competence, appearance, sports competence and strength. Low levels of physical activity have been linked to poor health and obesity, heart disease, eating disorders and depression. These findings are also consistent with the results of other studies that confirm physical selfconcept intimately associated with physical activity and other related factors of physical self-concept. ${ }^{28,26,25}$

\section{CONCLUSION}

Study concluded that obese category students were having poor selfconcept. Normal-weight students perceived higher physical self-concept and global self-esteem than obese and underweight students. Physical activity has strong association with sports competence, strength, appearance and self-esteem. Students engaged more time in physical activity had better physical self-concept.

\section{ACKNOWLEDGEMENT}

The authors would like thank the support provided by the Deanship of Scientific Research (DSR) at King Fahd University of Petroleum and Minerals, Dhahran for funding this work through Research Grant (IN151029).

\section{CONFLICT OF INTEREST}

The authors declare no conflict of interest.

\section{ABBREVIATIONS}

A-underweight, B-Normal weight, C-Obese and D-Obese-III.

\section{REFERENCES}

1. Shavelson RJ, Hubner JJ, Stanton GC. Self-concept: Validation of construct interpretations. Rev Educ Res. 1976;46(3):407-41.

2. Broderick PC, Blewitt $P$. The emerging self and socialization in the early years The Life Span: Human Development for Helping Professionals. 2006:144-74.

3. Marsh HW. A multidimensional physical self-concept: A construct validity approach to theory, measurement and research. Psychology: J Hellenic Psychol Soc. 2002;9(4):459-93.

4. Marsh HW, Chanal JP, Sarrazin PG. Self-belief does make a difference: A reciprocal effects model of the causal ordering of physical self-concept and gymnastics performance. J Sports Sci. 2006;24(1):101-11.

5. Babic MJ, Morgan PJ, Plotnikoff RC, Lonsdale C, White RL, Lubans DR. Physical activity and physical self-concept in youth: systematic review and metaanalysis. Open Access J Sports Med. 2014;44(11):1589-601.

6. Caspersen CJ, Powell KE, Christenson GM. Physical activity, exercise and physical fitness: definitions and distinctions for health-related research. Public Health Rep. 1985;100(2):126.

7. Rosenbaum S, Tiedemann A, Ward PB. Meta-analysis physical activity interventions for people with mental illness: A systematic review and meta-analysis. Clin Psychiatry. 2014;75(0):1.

8. Ortega FB, Ruiz JR, Castillo MJ, Sjöström M. Physical fitness in childhood and adolescence: A powerful marker of health. Int J Obes. 2008;32(1):1.

9. Trudeau F, Shephard RJ. Physical education, school physical activity, school sports and academic performance. Int J Behav Nutr Phys Act. 2008;5(1):10.

10. Sundblad GB, Jansson A, Saartok T, Renström P, Engström LM. Self-rated pain and perceived health in relation to stress and physical activity among schoolstudents: A 3-year follow-up. J Pain. 2008;136(3):239-49.

11. Waxman A. WHO global strategy on diet, physical activity and health. Food Nutr Bull. 2004;25(3):292-302.

12. Buckworth J, Nigg C. Physical activity, exercise and sedentary behavior in college students. J Am Coll Health. 2004;53(1):28-34.

13. Calfas KJ, Sallis JF, Lovato CY, Campbell J. Physical activity and its determinants before and after college graduation. Med Exerc Nutr and Health. 1994;3:323-34

14. Craven RG, Marsh HW. The centrality of the self-concept construct for psychological wellbeing and unlocking human potential: Implications for child and educational psychologists. Educational and Child Psychology. 2008;25(2):104-18.

15. Marsh HW, Papaioannou A, Theodorakis Y. Causal ordering of physical selfconcept and exercise behavior: Reciprocal effects model and the influence of physical education teachers. Health Psychol. 2006;25(3):316.

16. Skaalvik EM, Rankin RJ. A test of the internal/external frame of reference model at different levels of math and verbal self-perception. Am Educ Res J. 1995;32(1):161-84

17. Dishman RK, Hales DP, Pfeiffer KA, Felton GA, Saunders R, Ward DS, et al. Physical self-concept and self-esteem mediate cross-sectional relations of physical activity and sport participation with depression symptoms among adolescent girls. Health Psychol. 2006;25(3):396.

18. Marsh HW, Martin AJ, Jackson S. Introducing a short version of the physical self-description questionnaire: new strategies, short-form evaluative criteria and applications of factor analyses. J Sport Exerc Psychol. 2010;32(4):438-82.

19. Standage M, Gillison FB, Ntoumanis N, Treasure DC. Predicting students' physi- 
cal activity and health-related well-being: A prospective cross-domain investigation of motivation across school physical education and exercise settings. $J$ Sport Exerc Psychol. 2012;34(1):37-60.

20. Ryan RM, Deci EL. Active human nature: Self-determination theory and the promotion and maintenance of sport, exercise and health. Intrinsic Motivation and Self-determination in Exercise and Sport. 2007;1-19.

21. AlOthaimeen Al, AlNozha M, Osman AK. Obesity: An emerging problem in Saudi Arabia. Analysis of data from the National Nutrition Survey. East Mediter Health J. 2007;13(2):441-8.

22. Al-Rethaiaa AS, Fahmy AE, Al-Shwaiyat NM. Obesity and eating habits among college students in Saudi Arabia: A cross sectional study. Nutr J. 2010;9(1):39.

23. Antony VC, Tomar R. A comparative analysis of participation motivation to physical activity and sports among university students. J Sport and Health. 2016;7(1):2-13

24. Marsh HW. Age and sex effects in multiple dimensions of self-concept: Preadolescence to early adulthood. J Educ Psychol. 1989;81(3):417.
25. Sonstroem RJ, Harlow LL, Josephs L. Exercise and self-esteem: Validity of model expansion and exercise associations. J Sport Exerc Psychol. 1994; 16(1):29-42.

26. Hayes SD, Crocker PR, Kowalski KC. Gender differences in physical self-perceptions, global self-esteem and physical activity: Evaluation of the physical self-perception profile model. J Sport Behav. 1999;22(1):1.

27. Sonstroem RJ, Speliotis ED, Fava JL. Perceived physical competence in adults: An examination of the Physical Self-Perception Profile. J Sport Exerc Psychol. 1992;14(2):207-21

28. Morano M, Colella D, Robazza C, Bortoli L, Capranica L. Physical self-perception and motor performance in normal-weight, overweight and obese children. Sand J Med Sci Spor. 2011;21(3):465-73.

29. Park J. Adolescent self-concept and health into adulthood. Health Rep-Stat Canada. 2003;14(Suppl):41-52.

30. Garn AC, McCaughtry N, Martin J, Shen B, Fahlman M. A Basic Needs Theory investigation of adolescents' physical self-concept and global self-esteem. Int J Sport Exerc Psychol. 2012;10(4):314-28.

Cite this article: Antony VC, Azeem K. Influence of Physical Activity Body Mass Index on Perceived Physical Self-Concept among Undergraduate Students of Saudi Arabia. Int. J. Pharm. Investigation. 2019;9(4):210-4. 